\title{
CHANGES IN THYROIDAL FUNCTION DURING ADAPTATION TO LARGE DOSES OF IODIDE *
}

\author{
By LEWIS E. BRAVERMAN $\dagger$ AND SIDNEY H. INGBAR $\ddagger$
}

\author{
(From the Thorndike Memorial Laboratory and the Second and Fourth [Harvard] Medical \\ Services, Boston City Hospital, and the Department of Medicine, Harvard Medical \\ School, Boston, Mass.)
}

(Submitted for publication January 23, 1963 ; accepted April 4, 1963)

In 1944, Morton, Chaikoff, and Rosenfeld first made the seemingly paradoxical observation that the addition of large quantities of inorganic iodide to suspending media inhibited the total incorporation of iodide into organic compounds by surviving slices of sheep thyroid gland (1). Four years later, Wolff and Chaikoff, whose names have come to designate this effect, demonstrated that a similar acute inhibitory response could be elicited in vivo by giving rats single doses of stable iodide sufficient to increase greatly the concentration of iodide in the plasma (2). As time passed and the concentration of iodide in the plasma declined below an apparently critical level, organic binding of iodine within the thyroid returned. Subsequently, it was shown that despite the maintenance of high plasma concentrations of iodide by the administration of repeated doses, inhibition of organic binding abated, and hormone formation resumed (3); this is the "escape" or "adaptation" phenomenon. Since the acute Wolff-Chaikoff effect occurs in man $(4,5)$, adaptation may also be presumed to occur, since the vast majority of patients given prolonged iodide therapy are able to maintain a euthyroid state.

Since the initial description of the Wolff-Chaikoff effect, several additional facts and hypotheses concerning it have been presented. Raben, in a group of ingenious experiments, provided evidence that the acute inhibition of organic binding depends more closely upon the intrathyroidal than

* Supported in part by research grant AM-00267-10 from the National Institute of Arthritis and Metabolic Diseases, Bethesda, Md.

$\dagger$ Recipient of the Van Meter Prize Essay Award; work presented in part at the annual meeting of the American Thyroid Association, Chicago, Ill., May 10, 1963. Present address: St. Elizabeth's Hospital, Brighton, Mass.

$\ddagger$ Investigator, Howard Hughes Medical Institute. upon the plasma iodide concentration. Thiocyanate, by discharging thyroidal iodide, restored organic binding, although the concentration of iodide in the plasma remained high (6). Subsequently, Galton and Pitt-Rivers demonstrated that the small quantities of organic iodine formed during the acute Wolff-Chaikoff effect were comprised of inordinately high proportions of monoiodotyrosine (MIT) and low proportions of diiodiotyrosine (DIT) and thyroxine (7). Serif and Kirkwood have proposed a possible mechanism for the acute Wolff-Chaikoff effect (8), but to date there have been no suggestions about how escape occurs. With a view to elucidating the mechanism of this escape, we undertook the present studies to assess the changes in thyroidal function in animals chronically exposed to large amounts of iodide.

The present experiments were designed to compare the thyroidal function of normal or iodinedeficient rats with that of rats adapted to large doses of iodide. For such comparisons, it was necessary to determine the absolute quantities of stable iodine entering each intrathyroidal iodine compartment both in control animals and in those adapted to iodide. In earlier experiments concerning the inhibitory effects of large doses of iodide and the escape from these effects, stable iodide was administered together with $\mathrm{I}^{131}$, and the metabolism of the stable dose in vivo was determined from the fate of the administered radioiodine $(2,3)$. This method had several disadvantages for the present studies. First, for experiments involving prolonged administration of large doses of iodide, this procedure would have required the use of prohibitive amounts of radioactivity. Second, $I^{131}$ accumulated by the thyroid during the period of adaptation would have obscured efforts to assess thyroidal function once the adaptation had occurred. Therefore, we decided 
to adapt animals to stable iodide in vivo and to study the biosynthetic activity of their thyroids in vitro, where thyroid glands could be exposed to iodide of known specific gravity. Nevertheless, it seemed likely that the glands of animals adapted to iodide would contain large quantities of stable iodide, vitiating direct quantitative comparisons between the biosynthetic activity of these glands and that of normal or iodine-deficient controls. We therefore decided to attempt to free both adapted and control thyroids of their entire content of inorganic iodide before studying their iodine metabolism in vitro, and sought methods to remove intrathyroidal iodide as completely as possible. The procedure ultimately adopted and the experiments leading to its use will be described below (see Depletion of thyroidal iodide).

\section{METHODS}

Animals. Experiments were performed in Caesareandelivered, male, Sprague-Dawley rats whose weights in individual experiments were closely matched, but ranged in different experiments between 150 and $200 \mathrm{~g}$. Control rats were maintained for 14 days on either a Purina Chow diet or a low-iodine diet ${ }^{1}$ and tap water ad libitum. These rats will be termed "normal controls" or "low-iodine controls," respectively. Rats adapted to large quantities of iodide received the same diet as their corresponding controls for 14 days, but were given $0.01 \%$ iodide (as $\mathrm{NaI}$ ) in drinking water ad libitum for the last 5 days and $500 \mu \mathrm{g}$ of iodide by injection 3 hours before sacrifice. These will be termed "adapted" rats.

In experiments with hypophysectomized rats, animals were maintained on the low-iodine diet for 10 days before hypophysectomy. ${ }^{2}$ After operation, the low-iodine diet was continued for 14 days. "Hypophysectomized controls" received tap water ad libitum, whereas "hypophysectomized adapted" rats received $0.05 \%$ iodide in drinking water for the last 7 days. All hypophysectomized rats received $2.5 \mathrm{mg}$ of cortisone acetate subcutaneously two days out of every three.

Incubation procedure. For studies of iodine accumulation, thyroid glands were incubated in 1.0 or $2.0 \mathrm{ml}$ of a Krebs-Ringer-phosphate (KRP) medium at $\mathrm{pH} 7.4$ containing $100 \mathrm{mg}$ glucose per $100 \mathrm{ml}$ (KRPG). Media were enriched with varying concentrations of both $I^{181}$ ( 1 to $100 \mu \mathrm{c}$ per $\mathrm{ml}$ ) and stable $\mathrm{NaI}$ (0 to $25,000 \mu \mathrm{g}$ per $100 \mathrm{ml}) .^{3}$ In some experiments, media also contained

${ }^{1}$ Low-iodine test diet, Nutritional Biochemicals Corp., Cleveland, Ohio.

2 Normal as well as hypophysectomized rats were obtained from the Charles River Laboratories, Cambridge, Mass.

${ }^{3}$ Analyses of the unenriched KRPG medium indicated that it contained approximately $5 \mu \mathrm{g}$ of iodine per $100 \mathrm{ml}$.
$1 \times 10^{-3} \mathrm{M}$ methimazole. Incubations were performed in small Erlenmeyer flasks in a metabolic shaker under $100 \%$ oxygen at $37^{\circ} \mathrm{C}$ for 2 hours.

Analytic methods. After incubation, thyroid glands were lightly blotted, frozen on dry ice, and quickly weighed. In experiments with methimazole added to the medium, whole thyroids were counted in a well-type scintillation counter, and their content of $\mathrm{I}^{131}$ was considered to be entirely in the inorganic form. In other experiments, thyroids were homogenized in a known, small volume of ice-cold human serum containing carrier iodide. Samples of homogenate were counted for measurement of total radioactivity. Other samples were subjected to filter-paper electrophoresis in Tris-maleate buffer at $\mathrm{pH}$ 8.6 for $2 \frac{1}{2}$ hours at $200 \mathrm{v}$. This method reliably separates small proportions of inorganic $\mathrm{I}^{131}$ from large proportions of organically bound $I^{131}$ (9). Inorganic $I^{131}$ moved anodally and was localized by staining duplicate electrophoretograms with $1 \%$ palladium chloride. Organically bound $\mathrm{I}^{131}$ remained at or near the origin. These zones were excised from electrophoretograms and were individually counted. Other samples of the thyroidal homogenate were mixed with equal volumes of $0.0007 \mathrm{M}$ barbital buffer ( $\mathrm{pH} 8.6$ ) containing $0.005 \mathrm{M}$ propylthiouracil (PTU) and were hydrolyzed overnight with trypsin. Thereafter, samples were subjected to ascending filterpaper (Whatman 1) chromatography in a butanol:2 N acetic acid solvent system (1:1). Chromatograms were scanned for $\mathrm{I}^{131}$, and the areas under individual peaks were identified and quantified by methods described in detail elsewhere (10). Other specimens, and occasionally segments of chromatographic strips of low total radioactivity, were counted in a well-type scintillation counter. Radioactivity in individual specimens was related, where appropriate, to that in the incubation medium.

Depletion of thyroidal iodide. Several experiments were performed to define methods that virtually free thyroid glands of control and adapted animals of inorganic iodide before the determination of their functional status by incubation in $\mathrm{I}^{131}$-containing media.

In initial experiments, rats fed Purina Chow were given $10 \mathrm{mg}$ of ip PTU, followed by inorganic $\mathrm{I}^{131}$. Subsequently, the thyroid glands, which had accumulated inorganic $\mathrm{I}^{131}$ and virtually no organic $\mathrm{I}^{131}$, were excised and allowed to leach in large volumes of ice-cold KRP. Under these conditions, the thyroid loses its ability to maintain concentration gradients for iodide (11). As shown in Figure 1, however, iodide diffused out of the thyroid relatively slowly; complete removal of intrathyroidal iodide could not be achieved even by 2 hours of leaching. Since longer leaching seemed undesirable, other methods were sought to remove intrathyroidal iodide. Five rats previously maintained for 10 days on a low-iodine diet were injected twice daily with a solution containing $500 \mu \mathrm{g}$ of inorganic $\mathrm{I}^{127}$ and $60 \mu \mathrm{c}$ of inorganic $\mathrm{I}^{231}$ in $0.2 \mathrm{ml}$ of physiological saline. Injections were con-

This contaminating concentration was therefore added to that produced by direct addition of iodide in estimating the final concentration of iodide in incubating media. 


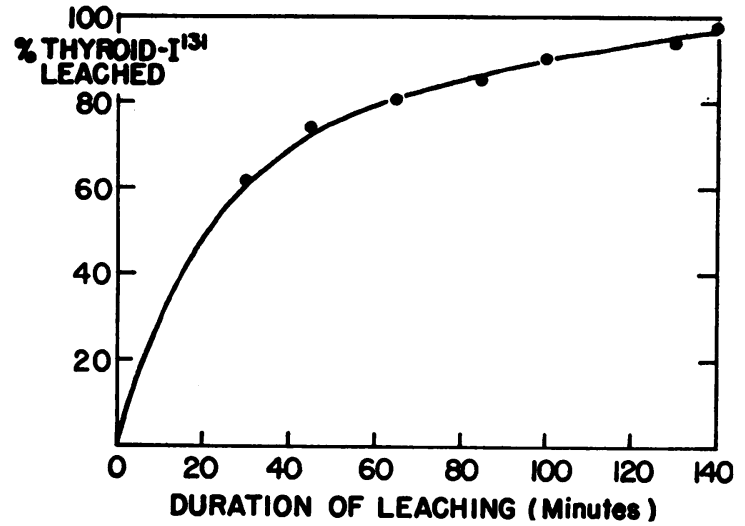

Fig. 1. LEACHING OF THYROIDAL IODIDE FROM PROPYLTHIOURACIL-BLOCKED RAT THYROID INTO COLD KREBSRinger-PHOSPHATE MEdiUm. Rats were given $10 \mathrm{mg}$ propylthiouracil 2 hours and $\mathrm{I}^{131} 1$ hour before sacrifice. Curve indicates cumulative loss of inorganic $I^{131}$ from a single thyroid into successive changes of $10 \mathrm{ml}$ of leaching medium.

tinued for $4 \frac{1}{2}$ days. A second group of 5 rats was injected once daily during the same period with a solution containing $10 \mu \mathrm{g}$ of inorganic $\mathrm{I}^{12 \pi}$ and $5 \mu \mathrm{c}$ of inorganic $\mathrm{I}^{131}$. The last injection of the $\mathrm{I}^{127}-\mathrm{I}^{181}$ mixture was made 3 hours before sacrifice. Two hours later, all rats received $20 \mathrm{mg}$ of ip potassium thiocynate (KSCN) and 1 hour later, were killed by a blow on the head. Thyroids were quickly removed, blotted, and placed in a beaker containing $10 \mathrm{ml}$ of cold KPR per thyroid. After 15 minutes, thyroids were transferred to a similar vessel for another 15 minutes, to a third vessel for 30 minutes, and to a fourth vessel for a final 30-minute leaching, with constant mild stirring of the medium. Then, thyroids were homogenized and analyzed for total radioactivity and for inorganic $\mathrm{I}^{181}$ as described above. Also, a sample of each leaching solution was counted. From the known specific activity of the original injection material and the radioactivity of each sample, the quantity of stable iodide in each could be calculated. Values obtained in the replicate groups from each treatment category agreed well. In rats that received the low dose of iodide, thyroids contained an average of $8.6 \mu \mathrm{g}$ of the administered iodine at the time of excision and $6.0 \mu \mathrm{g}$ after leaching, of which $0.011 \mu \mathrm{g}$ was present as iodide. In rats that received the high dose of iodine, thyroids contained an average of $12.2 \mu \mathrm{g}$ of administered iodine at the time of excision and $9.3 \mu \mathrm{g}$ after leaching, of which $0.025 \mu \mathrm{g}$ was present as iodide. Thus, although rats in the high-dose group received about 80 times as much iodide as the lowdose group, intrathyroidal iodide after $\mathrm{SCN}^{-}$and leaching was only twice that found in the low-dose group. Furthermore, less of the administered iodide was contained in each thyroid than was present as a contaminant in $1 \mathrm{ml}$ of the KRP buffer. The administration of $\mathrm{SCN}^{-}$in vivo followed by leaching in vitro was therefore considered to remove intrathyroidal iodide effectively, even in animals exposed to large doses of iodide for several days. The procedure described immediately above, the "standard thyroidal iodide-depletion procedure," was therefore used in many of the subsequent experiments.

Before this procedure could be employed as a standard method, however, we had to determine whether any residual action of $\mathrm{SCN}^{-}$administered in vivo could be detected in vitro. Twenty rats were divided into two groups. One group received $20 \mathrm{mg}$ of ip $\mathrm{KSCN} 1$ hour before sacrifice. The second group was retained as controls. After sacrifice, thyroids were removed, subjected to leaching as above, and incubated in KRPG containing $\mathrm{I}^{131}$. Thyroids of animals that had received $\mathrm{KSCN}$ in vivo accumulated an average of $18.0 \pm 5.8 \%$ (mean $\pm \mathrm{SD}$ ) of the $\mathrm{I}^{131}$ in the incubation medium. Thyroids from animals that did not receive $\mathrm{KSCN}$ accumulated $19.1 \pm 3.8 \%$ of the medium iodide. Thus, the in vivo administration of

TABLE I

The effect of prolonged exposure of rats to large doses of iodide on the in vitro thyroid uptake of carrier-free $I^{131 *}$

\begin{tabular}{|c|c|c|c|c|c|c|c|c|c|}
\hline \multirow[b]{2}{*}{ Exp't } & \multirow[b]{2}{*}{ Diet } & \multicolumn{5}{|c|}{ Thyroid uptake as percentage of medium I $^{181}$} & \multicolumn{3}{|c|}{ I $^{131}$-MIT /I'131-DIT $\ddagger$} \\
\hline & & Control & Acute & $\mathrm{p} \dagger$ & Chronic & $\mathrm{p}$ & Control & Acute & Chronic \\
\hline \multicolumn{10}{|l|}{ no. } \\
\hline 4 & Purina $[10]$ & $18.5 \pm 5.7$ & $22.6 \pm 6.1$ & $\mathrm{NS}$ & $13.0 \pm 3.7$ & $<0.025$ & 1.5 & 1.2 & 1.5 \\
\hline 6 & Purina $[15]$ & $20.8 \pm 6.1$ & & $\mathrm{NS}$ & $14.5 \pm 3.3$ & $<0.005$ & 1.3 & & 1.5 \\
\hline 7 & Purina $[10]$ & $25.7 \pm 8.7$ & $26.9 \pm 6.9$ & $\mathrm{NS}$ & $15.8 \pm 6.3$ & $<0.01$ & 1.2 & 1.2 & 1.3 \\
\hline $\begin{array}{l}17 \\
30\end{array}$ & Low-iodine [5] & $477+66$ & $52.0 \pm 12.5$ & & $28.0 \pm 7.0$ & $<0.01$ & & & \\
\hline $\begin{array}{l}30 \\
24\end{array}$ & $\begin{array}{l}\text { Low-lodine }[5] \\
\text { Low-iodine }[5]\end{array}$ & $\begin{array}{l}47.7 \pm 6.6 \\
28.8 \pm 2.3\end{array}$ & & & $\begin{array}{l}14.8 \pm 1.7 \\
10.1 \pm 2.0\end{array}$ & $\begin{array}{l}<0.001 \\
<0.001\end{array}$ & $\begin{array}{l}1.5 \pm 1.2 \\
1.6 \pm 0.2\end{array}$ & & $\begin{array}{l}1.3 \pm 0.1 \\
1.9+0.5\end{array}$ \\
\hline
\end{tabular}

* "Control" groups received indicated diet plus tap water for 14 days. "Acute" groups received, in addition, $500 \mu \mathrm{g}$ of ip stable iodide 3 hours before sacrifice. "Chronic" groups received designated diet, $0.01 \%$ iodide in the drinking water for 5 days, and $500 \mu \mathrm{g}$ of ip stable iodide 3 hours before sacrifice. All thyroids were subjected to standard thyroidal iodide-depletion procedure (see text) before incubation with $\mathrm{I}^{131}$. Values represent mean \pm standard deviation. Numbers in brackets indicate number of rats in each group.

$\dagger$ Significance of difference between indicated group and control group, except in experiment 17.

$\ddagger$ Values for experiments 4, 6, and 7 represent mean of 2 thyroid pools in each group. In other experiments, individual thyroids were analyzed. MIT and DIT = mono- and diiodotyrosine, respectively. 
TABLE II

The effect of prolonged exposure of rats to large doses of iodide on in vitro thyroid/medium concentration ratios for carrier-free inorganic $I^{131}$ in the presence of $1 \times 10^{-3} \mathrm{M}$ methimazole*

\begin{tabular}{|c|c|c|c|c|c|c|}
\hline \multirow[b]{2}{*}{ Exp't } & \multirow[b]{2}{*}{ Diet } & \multicolumn{5}{|c|}{ Thyroid/medium I121 concentration ratio } \\
\hline & & Control & Acute & $\mathbf{p}$ & Chronic & $\mathbf{p}$ \\
\hline $\begin{array}{r}n o . \\
8 \\
9 \\
22 \\
21 \\
26 \\
28 \\
17\end{array}$ & $\begin{array}{l}\text { Purina }[10] \\
\text { Purina }[10] \\
\text { Purina [5] } \\
\text { Low-iodine } \\
\text { Low-iodine } \\
\text { Low-iodine } \\
\text { Low-iodine }\end{array}$ & $\begin{array}{r}9.9 \pm 2.3 \\
11.6 \pm 4.5 \\
6.1 \pm 2.1 \\
89.3 \pm 29.0 \\
40.9 \pm 24.0 \\
60.7 \pm 16.9\end{array}$ & $\begin{array}{l}11.9 \pm 6.2 \\
13.0 \pm 2.6\end{array}$ & $\begin{array}{l}\text { NS } \\
\text { NS }\end{array}$ & $\begin{array}{r}7.2 \pm 2.0 \\
7.2 \pm 2.8 \\
3.0 \pm 0.8 \\
10.1 \pm 5.3 \\
6.9 \pm 2.9 \\
5.6 \pm 2.0 \\
18.1 \pm 4.5\end{array}$ & $\begin{array}{l}<0.01 \\
<0.025 \\
<0.01 \\
<0.001 \\
<0.025 \\
<0.001 \\
<0.01\end{array}$ \\
\hline
\end{tabular}

* Conditions as in Table I, except that standard thyroidal iodide-depletion procedure was not done in experiment 28.

KSCN did not appreciably influence the subsequent ability of excised and leached thyroid glands to accumulate inorganic $\mathrm{I}^{181}$ in vitro. This result was not unexpected, since the thyroid does not actively concentrate $\operatorname{SCN}^{-}(12,13)$, and any $\mathrm{SCN}^{-}$in the gland at the time of removal from the animal should be free to diffuse into the medium during leaching.

\section{EXPERIMENTS AND RESULTS}

Effect of adaptation to iodide on the in vitro accumulation of carrier-free $I^{131}$. Table I describes the results of 6 experiments on the accumulation of carrier-free $\mathrm{I}^{131}$ in vitro in thyroids of normal and low-iodine controls, rats adapted to iodide, and rats given a single large dose of iodide acutely. All thyroids were subjected to the standard thyroidal iodide-depletion procedure. Total uptake of $\mathrm{I}^{131}$ was always significantly lower, according to $t$ test (14), in the thyroids of adapted rats than in those of controls or of rats given iodide acutely. Uptake of $\mathrm{I}^{\mathbf{1 3 1}}$ in the latter two groups did not differ significantly. The ratio of I $^{131}$-labeled MIT to I $^{131}$-labeled DIT (MIT/ DIT) did not differ appreciably in the three groups.

Effect of adaptation to iodide on thyroid/medium concentration gradients for carrier-free $I^{131}$. Table II describes the results obtained in 7 experiments in which thyroids subjected to the standard thyroidal iodide-depletion procedure were then incubated in KRPG containing carrierfree $\mathrm{I}^{131}$ and $1 \times 10^{-3} \mathrm{M}$ methimazole. Thyroid/ medium iodide concentration ratios $(T / M)$ were significantly greater in thyroids of low-iodine than of normal controls, but in both groups were greatly reduced by adaptation to iodide. $\mathrm{T} / \mathrm{M}$ ratios in thyroids of animals given a single dose of iodide acutely did not differ significantly from those in corresponding normal controls.

Effect of adaptation to iodide on the in vitro metabolism of varying concentrations of inorganic iodide. Experiments were performed in lowiodine control and adapted animals. Thyroids were subjected to the standard thyroidal iodidedepletion procedure and were then incubated in KRPG containing inorganic $\mathrm{I}^{131}$ and varying concentrations of inorganic $\mathrm{I}^{127}$. Findings in one of two experiments that gave similar results are shown in Figure 2. Percentile uptake of $\mathrm{I}^{131}$ in both control and adapted thyroids decreased progressively as the concentration of iodide in the medium increased. $\mathrm{I}^{\mathbf{1 3 1}}$ uptakes in the thyroids of adapted animals, however, were significantly lower than in control groups at all concentrations of iodide added ( $p<0.001$ to $p=0.005)$. In both groups, total $\mathrm{I}^{127}$ accumulation, determined as the product of the total medium $\mathrm{I}^{127}$ content and the percentile uptake of $\mathrm{I}^{131}$, increased progressively with increasing concentrations of iodide in the medium, but at all concentrations of added iodide, was far lower in thyroids of adapted animals than of controls $(p<0.001$ to $p=0.005)$. The percentage of accumulated iodine organically bound in control thyroids was initially high, but decreased rapidly as the concentration of iodide in the medium was increased. In thyroids of adapted animals, the percentage of organic binding of accumulated iodine was initially slightly lower than in control thyroids, but decreased more gradually as the iodide concentration in the medium increased. Thus, it soon exceeded that in the control group ( $p<0.01$ to 0.001 ). The total quantity of iodine organically bound in control thyroids, calculated 
as the product of total iodine accumulation and the percentage of organic binding, increased with slight increases in medium iodide concentration and then declined, demonstrating a pattern characteristic of the Wolff-Chaikoff effect. In adapted thyroids, organic iodinations were initially far lower than in control thyroids ( $p$ $<0.001$ ), but increased progressively over a wider range of increase in medium iodide concentration than was the case in controls. In these adapted thyroids, total organic iodinations did not decline even at the highest concentrations of added iodide. Thus, at the higher iodide concentrations of the medium, organic iodinations in thyroids of adapted rats exceeded those found in controls $(p<0.005)$. These findings were consistent with an in vitro demonstration of escape from the Wolff-Chaikoff effect. Ratios of MIT/ DIT in the organic $\mathrm{I}^{131}$ of control thyroids averaged $1.5 \pm 0.2$ in carrier-free $I^{131}$. At the next higher concentration of medium iodide (30 $\mu \mathrm{g}$ per $100 \mathrm{ml}$ ), at which average organic iodinations increased, average MIT/DIT increased slightly. Inspection of individual results, however, showed this increase to be due to high ratios in two thyroids in which organic iodinations were no greater than in the previous group at the lower medium iodide concentration. These two thy-

0-o Iodine-Deficient Controls

$\longrightarrow$ Adapted to Iodide
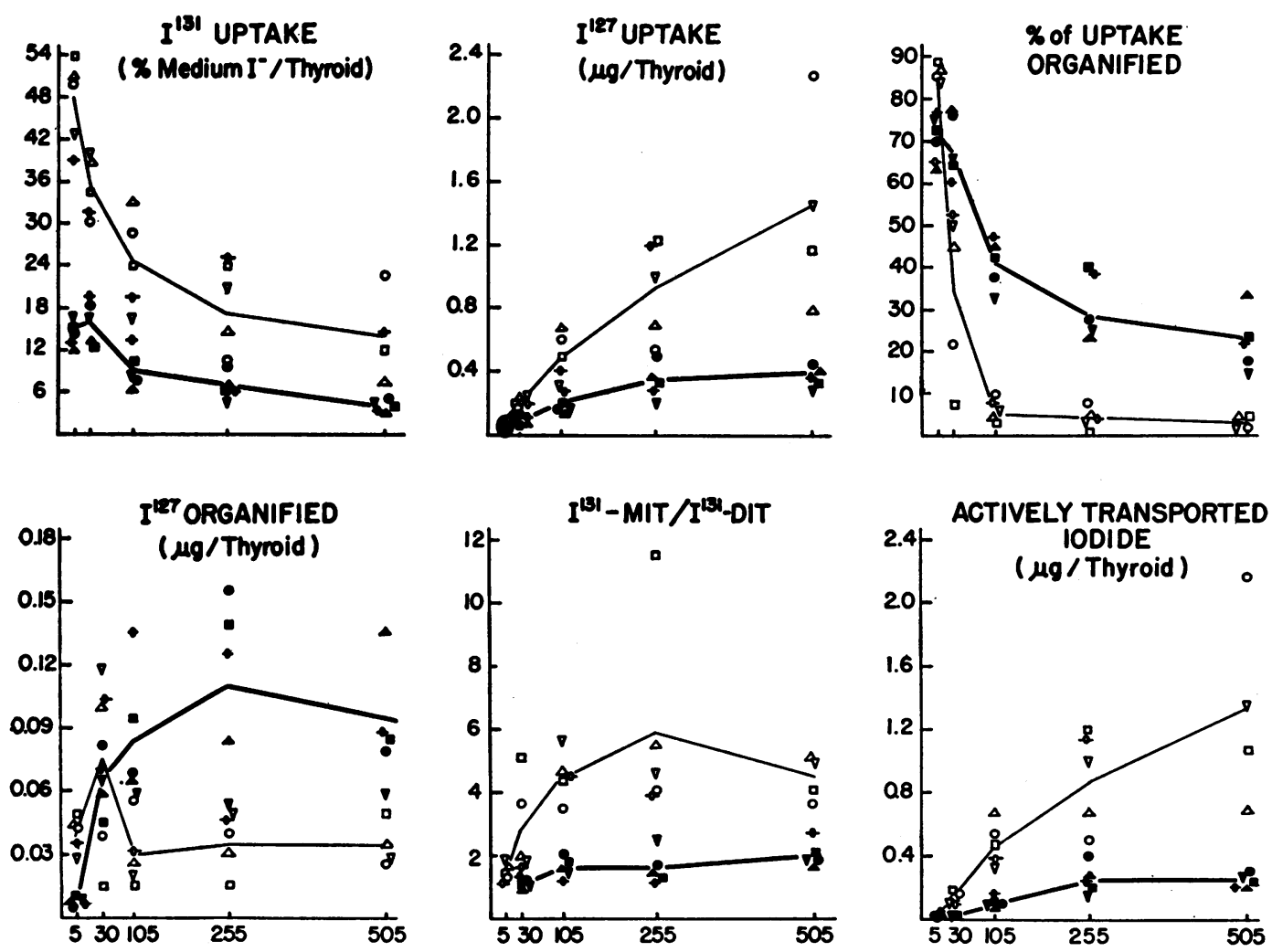

\section{IODIDE IN MEDIUM ( $\mu \mathrm{g} / 100 \mathrm{~mL}$ )}

Fig. 2. In vitro METABOLISM OF IODINE BY THYROIDS OF IODINE-DEFICIENT RATS AND RATS ADAPTED TO LARGE DOSES OF IODIDE. Iodine-deficient controls received low-iodine diet for 14 days. Adapted rats also received $0.01 \%$ iodide in the drinking water for 5 days. Standard thyroidal iodide-depletion procedure was performed (see text). For each concentration of iodide in the medium, each symbol depicts the value for the indicated function in the same single thyroid gland. Actively transported iodide was calculated from total inorganic $\mathrm{I}^{12 \pi}$ accumulation by assuming an iodide diffusion space equal to $40 \%$ of gland weight. Lines connect mean values at each iodide concentration in the medium. MIT and DIT $=$ mono- and diiodotyrosine, respectively. 


\section{0-0 Iodine-Deficient Controls $\quad-0$ Adapted to Iodide}
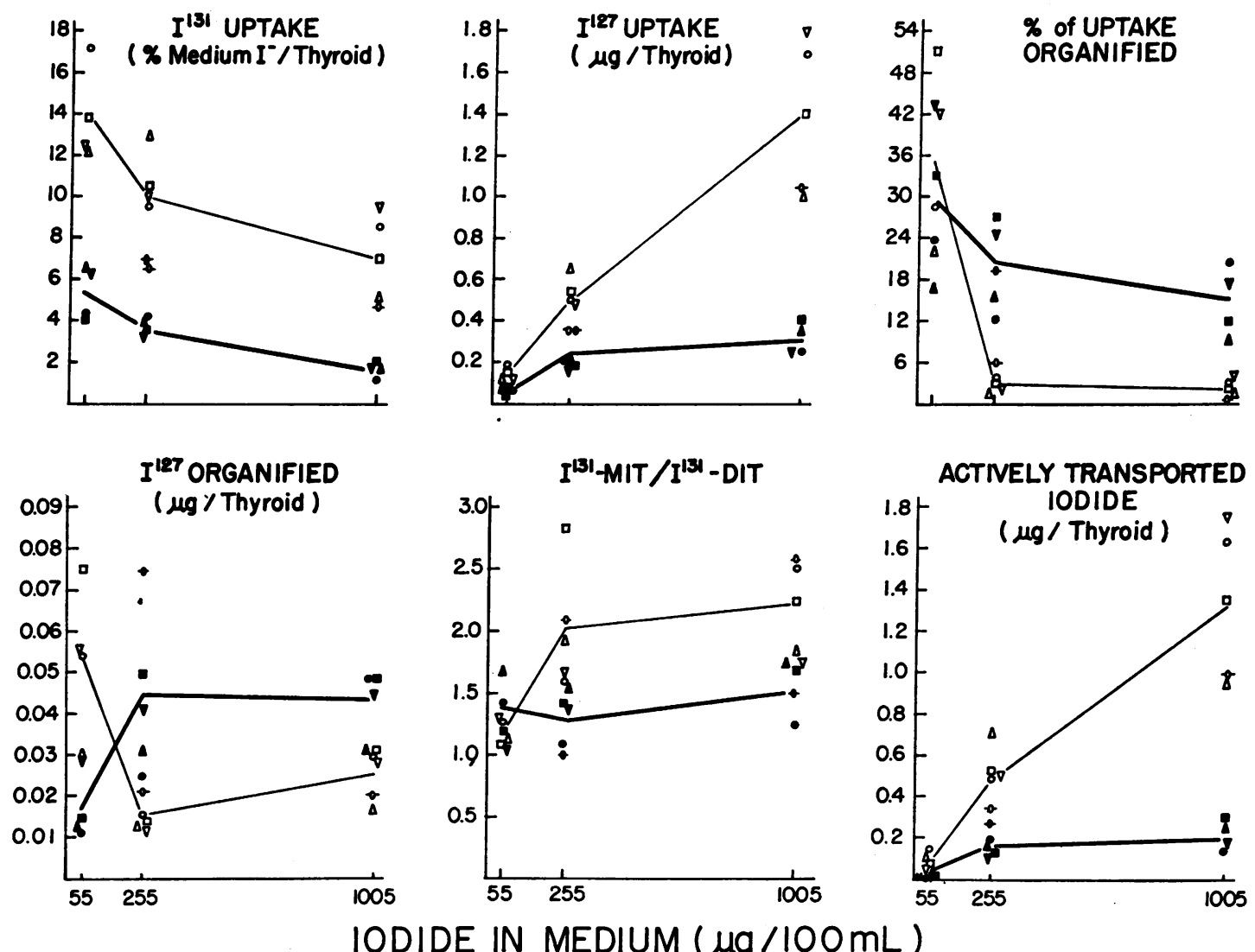

FIG. 3. In vitro METABOLISM OF IODINE BY THYROIDS OF IODINE-DEFICIENT RATS AND RATS ADAPTED TO LARGE DOSES OF IODIDE. Experimental design is similar to that for Figure 2, except that standard thyroidal iodide-depletion procedure was not performed.

roids appeared to be inordinately sensitive to the Wolff-Chaikoff effect. At the next higher iodide concentration in the medium (105 $\mu \mathrm{g}$ per $100 \mathrm{ml}$ ), at which the Wolff-Chaikoff effect was evident in average organic iodinations, MIT/DIT ratios were uniformly increased $(4.5 \pm 0.7, \mathrm{p}<$ 0.001). Ratios remained elevated at even higher iodide concentrations in the medium. In adapted thyroids, ratios averaged $1.5 \pm 0.1$ at the lowest medium iodide concentration and did not rise significantly as the iodide concentration in the medium was increased. Thyroidal accumulation of inorganic $\mathrm{I}^{131}$ was calculated by subtracting total organic iodinations from total iodine accumulation. The results thus obtained, expressed as micrograms $\mathrm{I}^{127}$ per thyroid, were corrected for iodide that had entered the thyroid by diffusion, based upon an iodide diffusion space equivalent to
$40 \%$ of the glandular weight (15). The resulting figure presumably represents the quantity of iodide actively transported into the thyroid. In control thyroids, this increased progressively with increasing iodide in the medium. In adapted thyroids, far less iodide was actively transported; a virtual plateau was achieved over the higher portion of the concentration range used in this experiment. Even at the highest iodide concentration in the medium ( $505 \mu \mathrm{g}$ per $100 \mathrm{ml}$ ), far less iodide $(p=0.005)$ was transported into adapted thyroids than into control thyroids at the much lower medium iodide concentration (105 $\mu \mathrm{g}$ per $100 \mathrm{ml}$ ) at which the Wolff-Chaikoff effect had already been induced. ${ }^{4}$ Similar results

4 The relationship between total transported iodide in control and adapted thyroids, as depicted in Figure 2 and subsequent figures, was not materially altered when the 
were obtained in three experiments carried out as above except that the thyroidal iodide-depletion procedure was omitted (Figure 3 ).

Effect of chronic exposure to iodide on thyroidal transport of inorganic iodide. Thyroids of low-iodine control rats and adapted rats were subjected to the thyroidal iodide-depletion procedure and then incubated in KRPG containing $10^{-3} \mathrm{M}$ methimazole, inorganic $\mathrm{I}^{131}$, and increasing concentrations of stable iodide. $\mathrm{T} / \mathrm{M}$ ratios were determined, and total iodide accumulation was calculated from the known concentration of iodide in the suspending medium. Actively transported iodide was calculated by subtracting from total iodide that estimated to have entered by diffusion. Similar results were obtained in two experiments; findings in one are shown in Figure 4. $\mathrm{T} / \mathrm{M}$ ratios in control thyroids were little affected by relatively small increases in medium iodide concentration, but declined progressively thereafter. A similar response to increasing io-

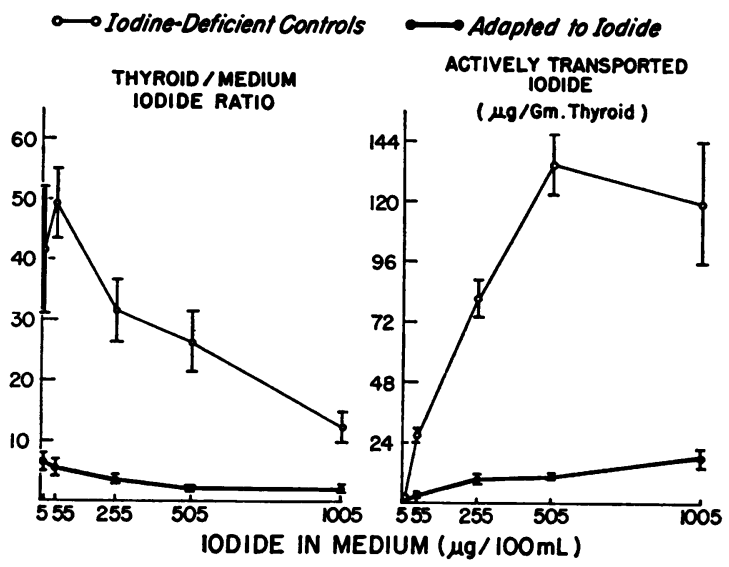

Fig. 4. EFfect of adaptation to LARge Doses of IODIDE ON IODIDE-TRANSPORT MECHANISM OF RAT THYROID GLANDS in vitro. After standard thyroidal iodide-depletion procedure, thyroids were incubated in Krebs-Ringerphosphate buffer containing $1 \times 10^{-3} \mathrm{M}$ methimazole. Individual points and I-bars indicate mean and standard error of values obtained in 5 thyroids at each of the indicated concentrations.

concentration, rather than the total quantity, of transported iodide was calculated. In all experiments, mean thyroid weights in adapted animals averaged only $11.6 \%$ less than the mean weight of low-iodine controls (range, 8.7 to $15.0 \%$ ). In experiments involving intact rats fed Purina Chow or hypophysectomized rats, differences in thyroid weights between control and adapted animals were even smaller.

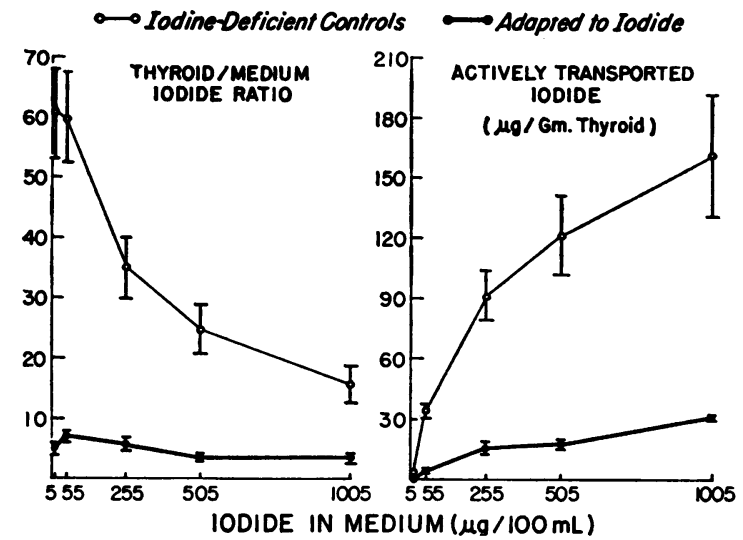

Fig. 5. EFFECT OF ADAPTATION to LARGE DOSES OF IODIDE ON THE IODIDE-TRANSPORT MECHANISM OF RAT THYROID GLANDS in vitro. Experimental design is similar to that in Figure 4, except that standard thyroidal iodide procedure was not employed.

dide in the medium was evident in adapted thyroids, but at all concentrations of added iodide, $\mathrm{T} / \mathrm{M}$ ratios in the latter group were far lower than in controls $(\mathrm{p}<0.01$ to 0.001$)$. In control thyroids, the quantity of iodide calculated to have been actively transported into the thyroid rose progressively and then appeared to reach a plateau at the highest iodide concentrations in the medium. A pronounced decrease in the concentration of actively transported iodide was evident in adapted thyroids ( $p<0.01$ to 0.001 ), where less iodide was concentrated in these glands at a medium concentration of $1,005 \mu \mathrm{g}$ per $100 \mathrm{ml}$ than in control thyroids at $55 \mu \mathrm{g}$ per $100 \mathrm{ml}$.

This difference between the iodide-transport capacity of control and adapted thyroids was also evident when the thyroidal iodide-depletion procedure was not used (Figure 5), and similar differences were noted in two experiments in which animals were given Purina Chow rather than a low-iodine diet. In normal control thyroids, however, $\mathrm{T} / \mathrm{M}$ ratios and total iodide transported were far less than in low-iodine controls.

Effect of chronic exposure to iodide in hypophysectomized rats. Studies were performed in hypophysectomized (low-iodine) control and hypophysectomized adapted rats. After the standard thyroidal iodide-depletion procedure, thyroids were incubated in KRPG containing inorganic $\mathrm{I}^{131}$ and varying concentrations of stable iodide. Findings in one of two experiments yielding similar results are shown in Figure 6. 
Except at the highest concentration of iodide employed, percentile accumulation of $\mathrm{I}^{131}$ was significantly greater in control than in adapted rats $(\mathrm{p}<0.05$ to 0.01$)$. Measurements of the percentile organic binding of accumulated iodine revealed pronounced differences between the two groups. At lower iodide concentrations in the medium, little difference was apparent. As the iodide concentration was increased, however, a significantly greater proportion of accumulated iodide was organically bound in adapted thyroids ( $p<0.01$ to 0.001 ). Calculation of the quantity of iodine organically bound in controls revealed no significant increase as the iodide concentration in the medium was increased from 55 to $2,505 \mu \mathrm{g}$ per $100 \mathrm{ml}$. In contrast, the quantity of iodine organically bound in adapted thyroids increased progressively, and at $2,505 \mu \mathrm{g}$ per $100 \mathrm{ml}$ was significantly higher than that found both in control thyroids at the same iodide concentration of the medium $(p<0.001)$ and in adapted thyroids at lower concentrations. In control thyroids, MIT/DIT ratios at the lowest iodide concentrations were greater than those in the thyroids of intact rats, which rose markedly at the highest iodide concentrations used. In adapted thyroids, MIT/DIT ratios were initially lower than in controls $(\mathrm{p}<0.005)$ and remained unchanged at all iodide concentrations in the medium. Calculated values for both the total amount and the concentration of iodide actively transported into the thyroids were significantly lower in adapted than in control glands at each of the medium iodide concentrations used ( $p<0.05$ to 0.01 ).

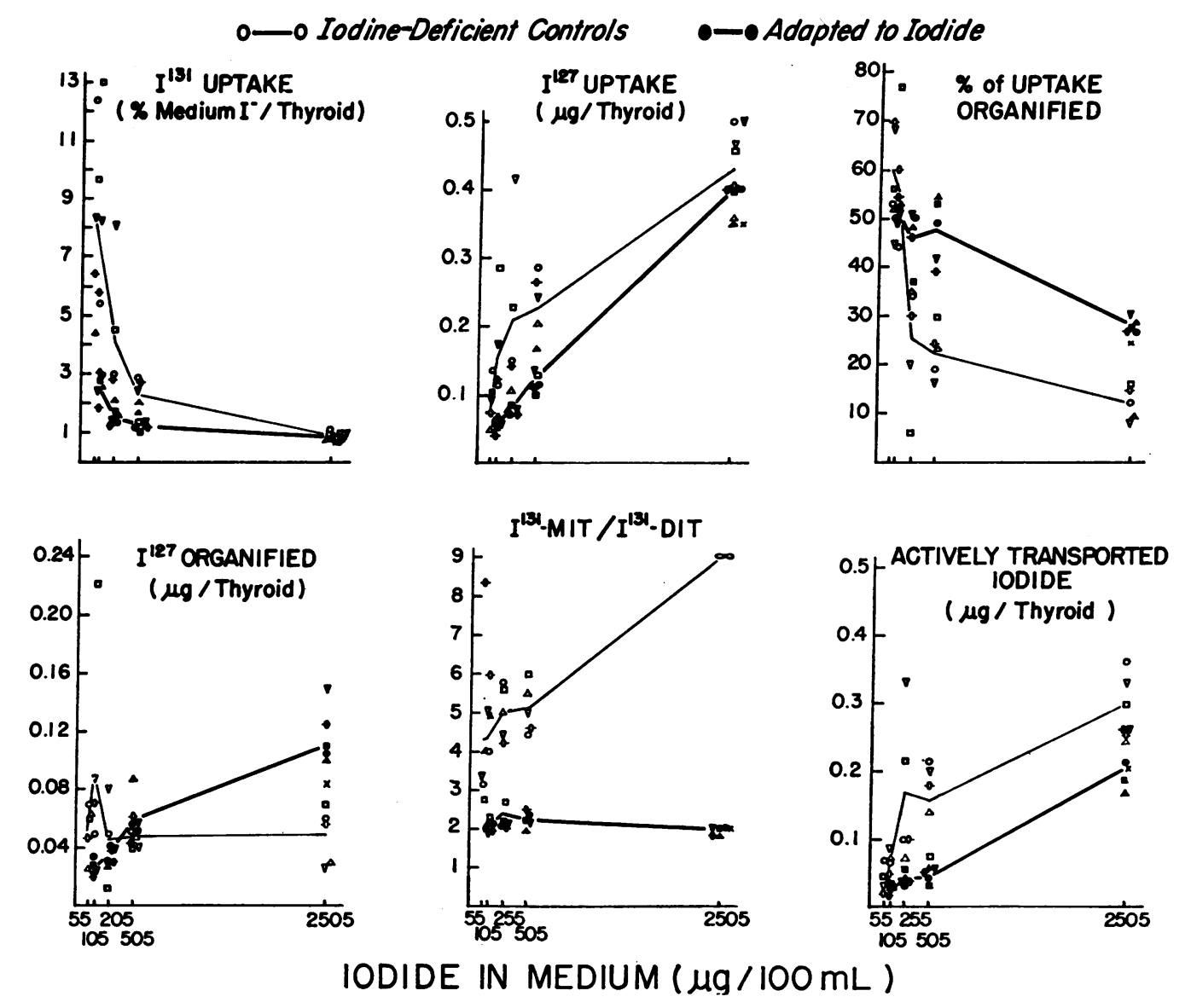

FIG. 6. In vitro METABOLISM OF IODINE BY THYROIDS OF IODINE-DEFICIENT HYPOPHYSECTOMIZED RATS AND HYPOPHYSECTOMIZED RATS ADAPTED TO LARGE DOSES OF IODIDE. All rats received low-iodine diet for 10 days before hypophysectomy. Control rats received the same diet for an additional 14 days, while adapted rats received, in addition, $0.05 \%$ iodide in the drinking water for 7 days. 


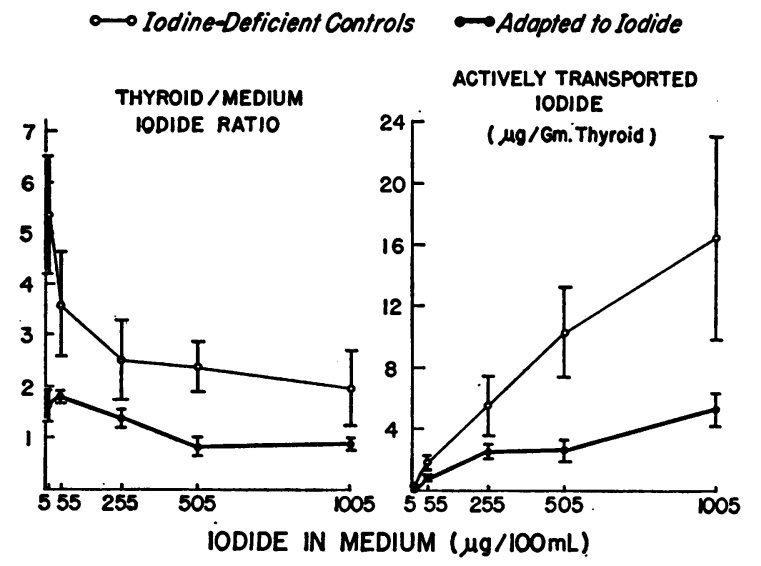

Fig. 7. EfFect of adaptation to LARge doses of IODIDE ON THE IODIDE-TRANSPORT MECHANISM OF THYROIDS FROM HYPOPHYSECTOMIZED RATS in vitro. Experimental groups are similar to those described for Figure 6 . Thyroids were incubated in media containing $1 \times 10^{-3} \mathrm{M}$ methimazole. Individual points and I-bars represent mean and standard error of values obtained in 5 thyroids at each of the indicated concentrations.

Iodide-transport capacity in thyroids of hypophysectomized control and hypophysectomized adapted animals was assessed by experiments similar to those described immediately above, except that media contained $10^{-3} \mathrm{M}$ methimazole (Figure 7). T/M ratios in thyroids of both control and adapted hypophysectomized rats were far lower than in thyroids of comparably treated intact rats. T/M ratios at each of the medium iodide concentrations averaged less in adapted than in control thyroids. Although there was little or no overlap of individual values in the two groups, considerable variation in values in control groups made the differences in the means statistically significant only at two iodide concentrations ( 5 and $505 \mu \mathrm{g}$ per $100 \mathrm{ml} ; \mathrm{p}=0.025$ and $<0.05$, respectively). Similar relationships were obtained when both the total quantity and the concentration of iodide actively transported were calculated.

Attempts to reinduce the Wolff-Chaikoff effect in adapted rats. Several attempts were made in intact rats to determine whether organic binding of iodine in thyroids of adapted rats could be inhibited by increasing the iodide concentration in the incubation medium to very high levels, but these failed to provide definite evidence of reinduction of blockade as assessed by either a de- crease in the amount of iodine organically bound, or a rise in the MIT/DIT ratio. Results were considered to be questionable, however, since at the very high iodide concentrations of the medium $\left(5,000\right.$ to $25,000 \mu \mathrm{g} \mathrm{I}^{-}$per $\left.100 \mathrm{ml}\right)$, small errors in determining the uptake of $\mathrm{I}^{131}$ or its percentile organic binding would produce very large errors in the calculation of the quantities of iodine that had entered the several intrathyroidal iodine compartments studied.

Since Raben had shown that thyroid stimulating hormone (TSH) facilitates induction of the Wolff-Chaikoff effect (6), in vitro metabolism of iodine was studied in an experiment in two groups of intact rats adapted to iodide for 5 days; one group was also treated with 7 U.S.P. U of TSH daily for the last 2 days before sacrifice. After the standard thyroidal iodide-depletion procedure, thyroids were incubated in KRPG containing $I^{131}$ and stable iodide in concentrations ranging from 30 to $10,005 \mu \mathrm{g}$ per $100 \mathrm{ml}$. Results are shown in Figure 8. In adapted rats, TSH did not significantly alter any of the functions studied. No evidence of reinduction of the Wolff-Chaikoff effect was obtained in either adapted or TSHtreated adapted groups; the quantity of organic iodine formed increased progressively, and MIT/ DIT ratios remained unchanged as the iodide concentration in the medium was increased.

Effect of chronic and acute exposure to iodide on the thyroidal metabolism of thiocyanate. Experiments were conducted in 12 low-iodine control and 12 adapted rats. Four hours before sacrifice, 6 rats from the control group received $0.2 \mathrm{ml}$ of ip physiological saline while the remaining 6 rats received $500 \mu \mathrm{g}$ of stable iodide (as $\mathrm{NaI}$ ). In the adapted group, 6 rats received $500 \mu \mathrm{g}$ of stable iodide, and the remaining 6 received $15 \mathrm{mg}$ of stable iodide. One hour later, all rats received $0.2 \mathrm{ml}$ of a solution of $\mathrm{S}^{35}$-labeled $\mathrm{SCN}^{-}(60 \mu \mathrm{c}$ in $1.9 \mu \mathrm{g})$. Rats were killed, thyroids were quickly removed, frozen on dry ice, and weighed. Individual thyroid glands were then homogenized in $300 \mu$ l of cold distilled water, and $25-\mu 1$ samples were subjected to ascending filter-paper (Whatman 1) chromatography in a $1 \mathrm{M}$ ethanol ammonium acetate $(\mathrm{pH} 7.5)$ system $(7.7: 3.0)$, as employed by Maloof and Soodak (13). Then, radioautographs were prepared, and from these, zones on the chromatograms corresponding to the 
point of application, to $\mathrm{SCN}^{-}$, and to sulfate were identified and excised. These segments were counted, under constant geometry, in a liquid scintillation counter with toluene and Liqueflor as the scintillating solution. All samples were counted for a uniform time; the probable counting error in individual samples therefore varied widely. For $\mathrm{S}^{35} \mathrm{CN}^{-}$, probable error did not exceed $2 \%$. For $\mathrm{S}^{35} \mathrm{O}_{4}^{--}$and protein-bound $\mathrm{S}^{35}$ $\left(\mathrm{PBS}^{35}\right)$, probable counting error of samples in which formation of these compounds was inhibited reached $15 \%$ in a few instances, but was usually far less. The administered $\mathrm{S}^{35} \mathrm{CN}^{-}$was also subjected to chromatography and found to be homogenous. Therefore, a sample of the administered dose was applied to filter paper and counted directly in the scintillation counter so that results could be expressed in terms of the quantity of $\mathrm{SCN}^{-}$administered.

Findings in one of two experiments with similar results are shown in Table III. Percentile accumulation of administered $\mathrm{S}^{35}$ was greatly decreased from control values in all three groups of rats that received iodide, either acutely or chronically. Such differences could not be ascribed to differences in the thyroidal content of $\mathrm{S}^{35} \mathrm{CN}^{-}$, since the percentile accumulation of this anion was virtually the same in all groups. Differences in the $\mathrm{S}^{35}$ content were ascribable to differences in the formation of the products of $\mathrm{SCN}^{-}$oxidation, i.e., $\mathrm{PBS}^{35}$ and $\mathrm{S}^{35} \mathrm{O}_{4}^{--}$, especially the latter. Both $\mathrm{S}^{35} \mathrm{O}_{4}^{--}$and $\mathrm{PBS}^{35}$ as a percentage of administered $\mathrm{SC}^{35} \mathrm{~N}^{-}$were greatly decreased from control values in all groups given iodide. In adapted
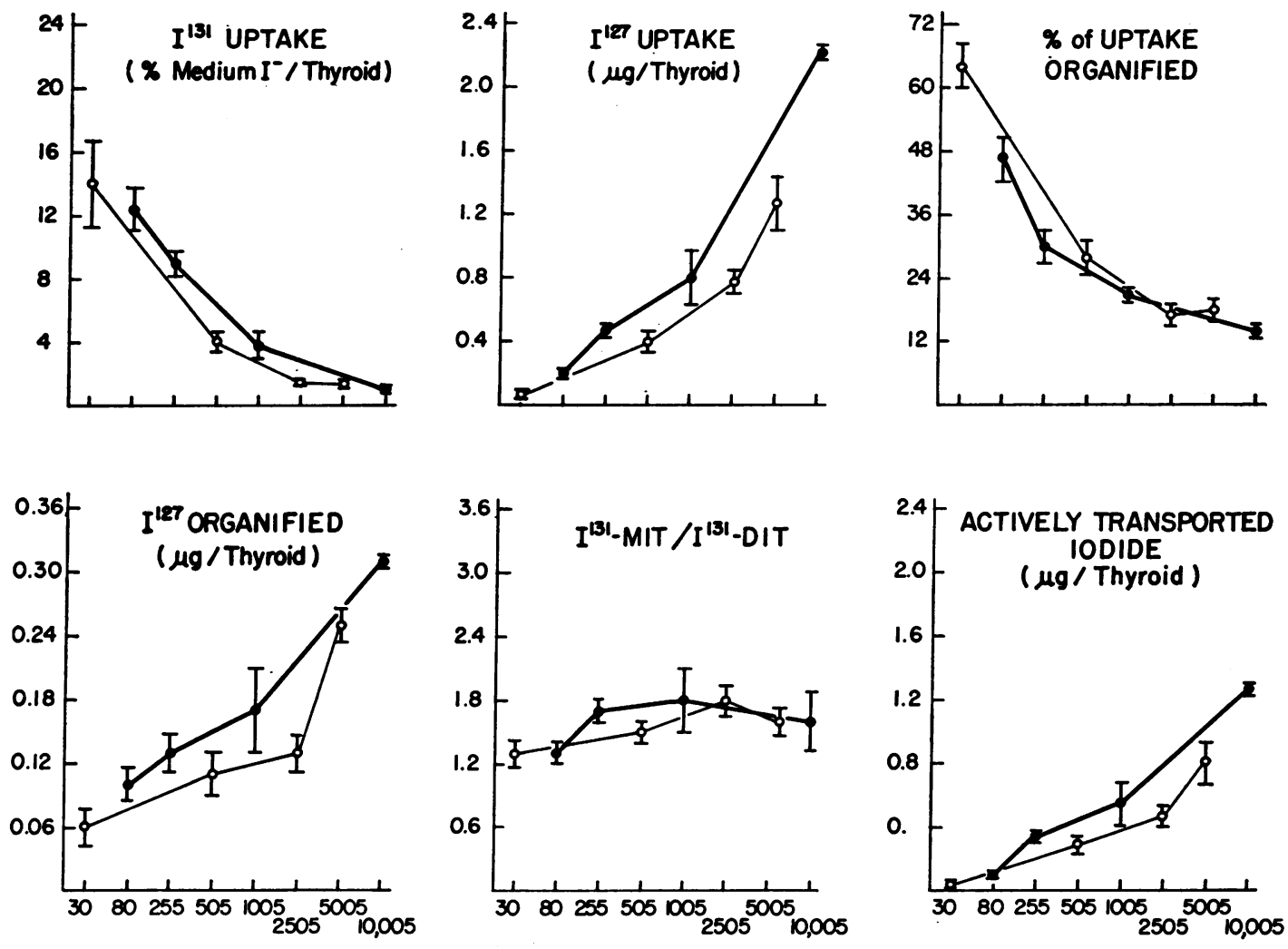

IODIDE IN MEDIUM ( $\mu \mathrm{g} / 100 \mathrm{~mL})$

Fig. 8. EFFect of THYROId-STIMUlating hormone (TSH) ON THE in vitro Metabolism of IOdine BY THYROIDS OF RATS ADAPTED TO LARGE DOSES OF IODIDE. Adapted controls received low-iodine diet for 14 days and $0.01 \%$ iodide in the drinking water for 5 days before sacrifice. TSH-treated animals received 7 U.S.P. U of TSH daily for 2 days before sacrifice. Individual points and I-bars represent mean and standard error of values obtained in 5 thyroids at each of the indicated concentrations. 
TABLE III

The effect of acute and prolonged exposure of rats to large doses of iodide on the thyroid metabolism of $S^{35}$-labeled thiocyanate in vivo*

\begin{tabular}{|c|c|c|c|c|}
\hline$\underset{(n=6)}{\text { Group }}$ & Total thyroidal & $\underset{\mathrm{S}^{25} \mathrm{CN}^{-}}{\text {Thyroidal }}$ & Thyroidal $\mathrm{S}^{25} \mathrm{O}_{4}^{--}$ & $\begin{array}{l}\text { Thyroid protein- } \\
\text { bound } S^{35}\end{array}$ \\
\hline & \multicolumn{4}{|c|}{$\%$ administered dose $\times 10^{4}$} \\
\hline $\begin{array}{l}\text { Control } \\
\text { Acute } \\
\text { Chronic } \\
\text { Chronic + acute }\end{array}$ & $\begin{array}{l}81 \pm 35 \\
19 \pm 5 \dagger \\
21 \pm 2 \dagger \\
17 \pm 3 \dagger\end{array}$ & $\begin{array}{l}15 \pm 2 \\
18 \pm 5 \\
14 \pm 2 \\
14 \pm 2\end{array}$ & $\begin{array}{ll}64 & \pm 34 \\
0.4 & \pm 0.2 \dagger \\
6 & \pm 2 \dagger \ddagger \\
3 & \pm 1 \dagger \ddagger 8\end{array}$ & $\begin{array}{l}2.4 \pm 0.9 \\
0.29 \pm 0.06 \dagger \\
0.43 \pm 0.07 \dagger \ddagger \\
0.34 \pm 0.07 \dagger\end{array}$ \\
\hline
\end{tabular}

* "Control" group received a low-iodine diet plus tap water for 14 days. "Acute" group received, in addition, 500 $\mu \mathrm{g}$ of ip stable iodide 3 hours before sacrifice. "Chronic" group received a low-iodine diet, $0.01 \%$ iodide in the drinking water for 5 days, and $500 \mu \mathrm{g}$ of ip stable iodide 3 hours before sacrifice. "Chronic + acute" group was treated like the chronic, except that the ip dose of iodide was $15 \mathrm{mg}$ rather than $500 \mu \mathrm{g}$. Values represent mean \pm standard deviation. $\dagger$ Significantly different from control group $(p<0.005)$.

¥ Significantly different from acute group $(\mathrm{p}<0.005)$.

$\S$ Significantly different from chronic group $(p<0.01)$.

rats, however, the accumulation of $\mathrm{S}^{35} \mathrm{O}_{4}^{--}$and $\mathrm{PBS}^{35}$ was significantly greater than in control rats given $500 \mu \mathrm{g}$ of iodide acutely. Administration of $15 \mathrm{mg}$ of stable iodide to adapted rats decreased formation of $\mathrm{S}^{35} \mathrm{O}_{4}^{--}$by more than $50 \%$; formation of $\mathrm{PBS}^{35}$ was slightly inhibited $(\mathrm{p}<$ $0.05)$. Nevertheless, formation of $\mathrm{S}^{35} \mathrm{O}_{4}^{--}$in adapted rats given $15 \mathrm{mg}$ of iodide acutely was still significantly greater than in control rats given an acute injection of only $50 \mu \mathrm{g}$ of iodide. Values for $\mathrm{PBS}^{35}$ in the latter two groups did not differ significantly.

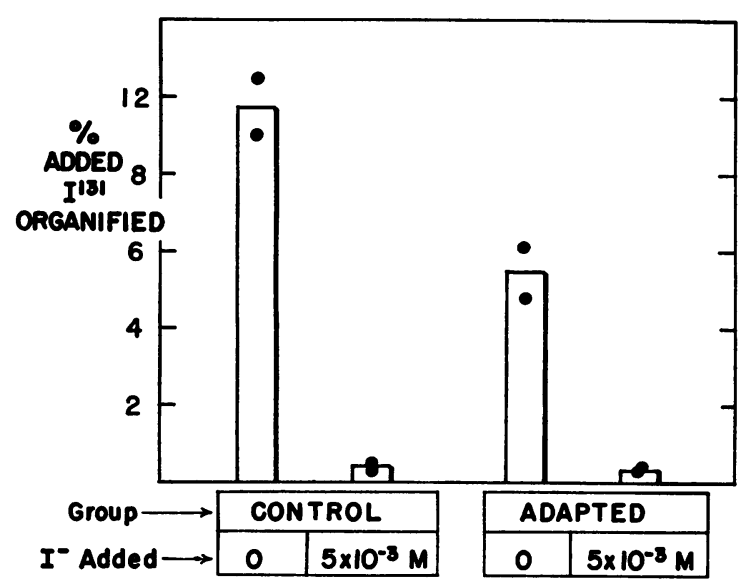

Fig. 9. EfFect of adaptation to LARge doses of IODIDE ON THE ORGANIC BINDING OF $\mathrm{I}^{131}$ BY HOMOGENATES OF RAT THYROID GLAND. Experimental groups were treated as described for Figure 2. Thyroids were subjected to standard thyroidal iodide-depletion procedure and then homogenized in groups of 5 . Single points represent values obtained in 2 separate homogenates for each group, one sample of which was enriched with stable iodide $\left(5 \times 10^{-3} \mathrm{M}\right)$.
Experiments with thyroid homogenates. Studies were performed in the thyroids from 10 normal control and 10 adapted rats. After sacrifice and removal of the thyroids, the standard thyroidal iodide-depletion procedure was used. Thyroids were then combined in two pools of five and were homogenized to a concentration of $5 \%$ (wt/vol) in a buffer rich in potassium, previously shown to support organic iodinations in thyroid homogenates (16). Samples of homogenates of control and adapted thyroids were enriched with stable $5 \times 10^{-3} \mathrm{M} \mathrm{NaI}$. Inorganic $\mathrm{I}^{131}$ was added, and the duplicate vessels were incubated at $37^{\circ} \mathrm{C}$ for 1 hour under $100 \%$ oxygen. At the end of incubation, $1 \times 10^{-2} \mathrm{M}$ methimazole was added to stop further iodinations. Percentile organic binding was analyzed by trichloroacetic acid (TCA)precipitation (16). Results are presented in Figure 9 . In vessels with no added iodide, percentile iodinations in homogenates of control thyroids exceeded those in adapted glands. In vessels supplemented with iodide, there was no difference between iodinations in the two groups.

\section{DISCUSSION}

$A$ proposed mechanism of the escape phenomenon. The rate of incorporation of iodine into the thyroid hormones or their iodotyrosine precursors can be considered to depend on two sequential processes: 1) active transport and concentration of inorganic iodide, and 2) oxidation and organic binding of intrathyroidal iodide. Thus, the ability of large doses of iodide to inhibit acutely the formation of hormone (Wolff-Chaikoff effect) must 
occur through alterations in one or both of these processes. It has been suggested that the acute Wolff-Chaikoff effect is due to a complexing of oxidized iodine in the presence of high concentrations of inorganic iodide to yield the $\mathrm{I}_{3}{ }^{-}$ion, which is incapable of carrying out iodinations (8). This hypothesis implies that the intrathyroidal, rather than the plasma, concentration is the critical determinant of this reaction. Raben's experiments support this conclusion by demonstrating that $\mathrm{SCN}^{-}$, by acutely lowering the intrathyroidal iodide, can restore hormone formation in the presence of high iodide concentrations in the plasma (6).

The escape from the inhibitory effects of iodide on hormone formation may also be expected to occur through a modification of either the iodide transport, or the organic-binding mechanism, or both. Thus, escape might occur if the organic binding were activated and thereby made less sensitive to the inhibitory effects of high concentrations of intrathyroidal iodide. The present experiments, however, provided no evidence that this was the case. In thyroid homogenates, where the iodide-transport mechanism is obliterated and organic-binding processes could be separately studied, adapted thyroids carried out organic iodinations no more efficiently than did controls, in either the presence or the absence of high concentrations of added iodide.

An activation of the iodide-transport mechanism would be expected to enhance the inhibition of organic binding by increasing intrathyroidal iodide. Thus, the iodide-transport mechanism could be the locus of adaptation only if its activity were to decrease, making the thyroid unable to retain sufficient quantities of iodide to sustain the WolffChaikoff effect. Several groups of experiments indicated that this was indeed the case. In carrierfree media, adapted thyroids, even when first freed of their intrathyroidal iodide, formed less organic iodine than did controls. This decrease in hormone formation could not be ascribed to a persistence of the Wolff-Chaikoff effect, since the MIT/DIT ratio of newly formed organic iodine was not abnormally high. Rather, it appears to be adequately explained by a lowering of the $T / M$ ratio maintained by the adapted glands, as attested by studies carried out in the presence of methimazole.
Although at low concentrations of extracellular iodide the hormonogenetic performance of adapted thyroids was poorer than that of controls, their superior potential was evident when they were exposed to the conditions of adaptation, i.e., high concentrations of extracellular iodide. In control thyroids, as iodide concentrations in the medium progressively increased, an acute Wolff-Chaikoff effect was induced. In adapted thyroids, the response to progressive increases in extracellular iodide differed greatly; far less iodine entered the thyroid, but of that accumulated, a greater proportion underwent organic binding. Hormone formation thus increased with progressively higher iodide concentrations in the medium. Furthermore, MIT/DIT ratios failed to increase. These findings were consistent with those occurring during the escape phenomenon in vivo, and provide the first demonstration that the functional changes leading to escape persist under in vitro conditions. Calculated values for both the quantity and the concentration of actively transported thyroidal iodide were far lower in the glands of adapted rats than in controls. In most experiments, intrathyroidal iodide in adapted glands, even at very high iodide concentrations in the medium, did not reach concentrations equal to those in control glands at the far lower medium iodide concentrations sufficient to produce the Wolff-Chaikoff effect. It might be argued that the lower concentrations of intrathyroidal iodide in adapted than in control thyroids, especially at higher iodide concentrations in the medium, merely reflect the superior ability of adapted thyroids to carry out organic iodinations, since inhibition of iodinations is itself associated with an increase in thyroidal iodide (17). This possibility was excluded, however, by the demonstration that the iodide-transport capacity of adapted thyroids was far lower than that of control glonds when it was assessed in a medium containing sufficient methimazole to inhibit organic iodinations completely.

No substantial difference was noted between results when thyroids were depleted of iodide before study and those when they were not. At the high iodide concentrations in the medium at which the major functional differences between adapted and control thyroids were evident, the difference between the iodide content of undepleted adapted and control thyroids may have been relatively 
insignificant. Also, the findings would indicate that the functional difference between adapted and control thyroids is not produced by a freely diffusible substance in the adapted gland.

The present experiments would thus suggest that the adaptive response to sustained high concentrations of extracellular iodide consists of a decreased thyroidal capacity to concentrate inorganic iodide. The mechanism of this naturally occurring escape would then be similar to that of the acute escape from the Wolff-Chaikoff effect brought about by administration of $\mathrm{SCN}^{-}$. In both cases, intrathyroidal iodide would be reduced to levels too low to block organic binding. Whatever the mechanism of this alteration in iodidetransport capacity, it subserves homeostatic requirements well, since inhibition of one phase of hormonogenesis permits a subsequent phase to resume.

The report of Wolff, Chaikoff, Goldberg, and Meier, who first demonstrated the escape phenomenon, reveals data consistent with the foregoing hypothesis in that resumption of organic binding is associated with a reduction in total glandular iodine (3). This resulted from a modest decline in what was considered to be thyroidal inorganic iodine. Viewed alone, such a decline might be attributed to resumption of organic binding. In that case, however, total thyroidal iodine should not have decreased. The magnitude of the decline in apparent inorganic iodide that these authors noted to coincide with escape seems small, and probably too small to account for escape. In these earlier experiments, however, the inorganic iodine fraction was determined by TCA-precipitation, and the TCA-soluble fraction in glands with organic $\mathrm{I}^{131}$ has recently been shown to contain an iodinated peptide in amounts exceeding that of true inorganic iodide by several times (9). It would be expected that the concentration of such TCA-soluble iodopeptides would be low before escape and that TCA-soluble $\mathrm{I}^{131}$ would be largely inorganic. As organic binding resumes, an increasing quantity of iodopeptides would be formed and would obscure, at least in part, the true decline in inorganic iodide associated with escape.

Reinduction of Wolff-Chaikoff blockade in adapted rats. The proposed mechanism of the escape phenomenon suggests that the adaptive response to chronic iodide administration repre- sents a quantitative, rather than a qualitative, alteration in thyroidal function. Theoretically, when extracellular iodide is sufficiently high, simple diffusion should restore intrathyroidal iodide to inhibitory concentrations. Failure to demonstrate reinitiation of blockade when, in the present experiments, adapted thyroids were incubated in very high concentrations of iodide constitutes the major source of doubt concerning the validity of the proposed mechanism for the escape phenomenon. On the other hand, there is great difficulty in calculating absolute rates of iodine metabolism in experiments in which the specific activity of $\mathrm{I}^{131}$ in the incubating medium is very low. Here, very small errors in the measurement of total $\mathrm{I}^{131}$ uptake or of percentile organic binding will profoundly affect calculated values for iodide accumulation and transport and for hormone formation.

In an effort to assess the oxidative mechanisms of the control and adapted thyroids under conditions in which the specific activity of iodide would not, per se, influence measurements, the experiments with $\mathrm{S}^{35}$-labeled $\mathrm{SCN}^{-}$were undertaken. In the thyroid, $\mathrm{SCN}^{-}$is not actively concentrated $(12,13)$, but it does undergo oxidation to yield protein-bound sulfur and sulfate $(12,13,18)$. The oxidative mechanisms for $\mathrm{SCN}^{-}$and for iodide share many properties and may occur through a common mechanism. Both are inhibited by antithyroid agents, such as thiouracil derivatives $(12,13,18)$, and both are stimulated by $\mathrm{TSH}(18)$. $\mathrm{SCN}^{-}$inhibits the oxidation of iodide $(16,19)$. Furthermore, as for iodide, the oxidation of $\mathrm{SCN}^{-}$is acutely inhibited by single large doses of iodide, suggesting that the acute Wolff-Chaikoff effect is reflected in the metabolism of $\mathrm{SCN}^{-}$(13). Since endogenous concentrations of $\mathrm{SCN}^{-}$are small (20) and are not known to be influenced by variations in iodide intake, absolute rates of $\mathrm{SCN}^{-}$oxidation can be calculated from the specific activity of administered $\mathrm{SCN}^{-}$, even though extracellular iodide concentrations vary widely. The present experiments have confirmed the Wolff-Chaikoff-like effect of large single doses of iodide on the oxidation of $\mathrm{SCN}^{-}$, first demonstrated by Maloof and Soodak (13). In addition, the data provide the first evidence that the inhibition of $\mathrm{SCN}^{-}$oxidation is partially ameliorated in animals adapted to iodide, a response resembling the escape from the Wolff-Chaikoff effect. The 
differences in the intrathyroidal accumulation of the products of $\mathrm{SCN}^{-}$metabolism cannot be asscribed to differences in the extrathyroidal disposition of $\mathrm{SCN}^{-}$, since concentrations of unchanged $\mathrm{SCN}^{-}$in the thyroids were virtually identical in all groups. Furthermore, it is highly unlikely that differences in the accumulation of $\mathrm{S}^{35} \mathrm{O}_{4}^{--}$could have resulted from differing rates of its accumulation from the plasma. Previous studies of the nature of serum $\mathrm{S}^{35}$ after administration of $\mathrm{S}^{35} \mathrm{CN}^{-}$have shown negligible quantities of $\mathrm{S}^{35} \mathrm{O}_{4}^{--}$to be present (13), and administered $\mathrm{S}^{35} \mathrm{O}_{4}^{--}$is concentrated by the thyroid from the serum only slightly (21). Thus, it may be that the presently demonstrated ability of high doses of iodide to decrease the intrathyroidal conversion of $\mathrm{SCN}^{-}$to $\mathrm{SO}_{4}^{--}$in rats adapted to iodide represents a reinduction of the Wolff-Chaikoff effect. This conclusion must remain tentative, however, since the precise relationship of the oxidation of iodide to that of $\mathrm{SCN}^{-}$is as yet uncertain.

The difficulties of accurately measuring total iodination and MIT/DIT ratios when iodide concentrations in the medium are high make the present inability to reinduce the Wolff-Chaikoff effect in adapted rats difficult to interpret. Aside from analytical error, however, a further explanation requires consideration. There appears to be a limit to the quantity of iodide that can be actively transported into the thyroid, since, with increasing concentrations of extracellular iodide, no further increases in transported iodide occur, although total thyroidal iodide increases by simple diffusion (15). Possibly, only the iodide that is actively transported into the thyroid is so spatially located or physicochemically constituted that it can inhibit the mechanism of organic binding. Iodide that enters the thyroid by diffusion may be unable to do so. If this were the case, then the profound lowering of the iodide-transport capacity of the adapted thyroid, as shown here, would have prevented reinduction of blockade, even at the highest practicable iodide concentrations in the medium.

Mechanism of reduction of iodide transport in adapted rats. Whether or not a reduction in iodide-transport capacity is truly responsible for the escape from the Wolff-Chaikoff effect, as the present data suggest, the mechanism of this reduction remains to be considered. The major regulator of the thyroidal iodide-concentrating mechanism is generally considered to be TSH, since suppression or removal of the pituitary decreases $\mathrm{T} / \mathrm{M}$ ratios and iodide-transport capacity, whereas administration of TSH stimulates these functions (17). Conceivably, then, administration of large doses of iodide to the iodine-deficient animals most commonly employed as controls in these and previous studies of the Wolff-Chaikoff effect may have resulted in diminished secretion of TSH that was reflected in decreased activity of the iodide-transport mechanism. The present and previous data would suggest, however, that other factors must be invoked. Thus, evidence of both the induction of the acute Wolff-Chaikoff effect and the escape from it was obtained in the thyroids of hypophysectomized rats, and the iodidetransport capacity of such thyroids, as assessed in vitro in the presence of methimazole, was decreased by the adaptation regimen. Furthermore, in vivo administration of large doses of TSH did not significantly influence the in vitro metabolism of iodine by adapted thyroids incubated in varying concentrations of extracellular iodide. If decreased secretion of endogenous TSH during adaptation were the sole source of the decreased iodide transport with adaptation, then exogenous TSH should restore this function and "unadapt" the thyroid gland. Instead, the findings suggest that changes in the secretion of TSH are not, per se, responsible for the escape from the WolffChaikoff effect.

The present data, on the other hand, are consonant with the hypothesis that adaptation to large doses of iodide results mainly from an intrinsic change in thyroidal function that modifies the response of TSH and is evident even in the absence of TSH. Recognition that such intrinsic regulation exists stems largely from the work of Halmi, Spirtos, Bogdanove, and Lipner (22-25) and of VanderLaan and Caplan (26), recently reviewed by Halmi and Stuelke $(17,27)$. These workers have shown that, both under stimulation by constant doses of TSH and in the absence of TSH, dietary or pharmacological regimens altering the organic iodine content of the thyroid inversely affect thyroid/plasma iodide concentration ratios. On this basis, it has been postulated that such autoregulation of iodide transport is effected by an iodinated organic inhibitor (17). Data of the 
present experiments in hypophysectomized and intact rats complement the data of these workers by showing the autoregulatory reduction in iodide transport induced by high-iodine diets to be demonstrable in vitro, both after the thyroid is virtually freed of inorganic iodide and in the presence of widely varying concentrations of extracellular iodide. Thus, they indicate that the iodidetransport capacity, and not merely the endogenous thyroid/plasma iodide concentration ratio, is reduced in rats (hypophysectomized or intact) fed high-iodine diets. The data further indicate that this inhibition of iodide transport is apparently great enough to account for the escape from the acute Wolff-Chaikoff effect.

As in previous studies of the Wolff-Chaikoff effect, the present observations have been conducted mainly in rats maintained on a low-iodine diet before the start of experiments $(2,3)$. Such rats are suitable for use, since they are highly sensitive to the acute inhibitory effects of iodine, probably because their thyroidal iodide-transport mechanism is highly active. In studies not reported here, thyroids from rats receiving a Purina Chow diet are far less sensitive to the induction of the acute Wolff-Chaikoff effect than are those of iodine-deficient rats. This reduced sensitivity can be at least partially ascribed to a lesser activity of the iodide-transport mechanism. Thus, in the context of the present observations and the hypotheses derived from them, rats fed Purina Chow may be considered to be partially adapted to iodide. Nevertheless, it is demonstrable that supplementation of the iodide intake in such rats results in both a further insensitivity to the acute inhibitory effects of iodide and a further decline in iodide transport. Such rats may be considered to be fully adapted to iodide in that the WolffChaikoff effect cannot be induced in their thyroids over the entire range of extracellular iodide concentrations at which measurements are feasible. Evidently, it is incorrect to think of animals as entirely unadapted or entirely adapted to iodide. Rather, there appears potentially to be a continuum of sensitivity to iodide, and this is related to the dietary intake and perhaps to the glandular content of organic iodine. Where within this continuum the truly normal range may lie is moot and, in the rat, may have little consequence. In man, however, the question assumes some impor- tance in view of the possibility that widespread dietary iodine supplementation may be considered as a mean of reducing the thyroidal accumulation of radioiodine derived from atmospheric contamination.

\section{SUM MARY}

Studies have been conducted to determine the mechanism whereby the acute inhibitory effect of large doses of iodide on the organic binding of thyroidal iodide (Wolff-Chaikoff effect) is overcome during prolonged iodide administration (adaptation or escape phenomenon). Thyroids of control rats and of rats adapted to iodide in vivo were freed of inorganic iodide by in vivo administration of thiocyanate and in vitro leaching, and were then incubated in media containing inorganic $\mathrm{I}^{131}$ of widely varying specific activity.

In vitro, when exposed to low concentrations of extracellular iodide, thyroids of control animals accumulated and organically bound more iodine than did adapted glands. As the extracellular iodide concentration was increased, the total iodine accumulation in control thyroids increased; however, the quantity of iodine bound organically ultimately declined. At this point, ratios of labeled mono-/diiodotyrosine rose. Thus, a Wolff-Chaikoff effect was induced in vitro in control glands. In adapted thyroids, far less iodine entered the thyroid, but especially at higher concentrations of extracellular iodide, the percentage of accumulated iodide bound organically did not decline so rapidly as in controls. As a result, total organic binding rose progressively and, at high iodide concentrations in the medium, exceeded that in control glands. Mono-/diiodotyrosine ratios did not increase. Thus, escape from the inhibitory effects of iodide was evident in vitro in adapted thyroids.

At each concentration of extracellular iodide, far less inorganic iodide was found in adapted than in control glands, and the concentration of thyroidal iodide achieved by adapted thyroids at the highest medium iodide concentrations used was far less than that sufficient to induce the Wolff-Chaikoff effect in control glands. In the presence of blocking concentrations of methimazole, the iodide-transport capacity of adapted thyroids was far lower than that of control glands. Qualitatively similar data were obtained in 
studies of the thyroids of control and adapted hypophysectomized rats. Administration of thyroidstimulating hormone to adapted rats did not alter their in vitro iodine metabolism, or their ability to resist the inhibitory effects of high concentrations of extracellular iodide.

These data suggest that adaptation to the inhibitory effects of large doses of iodide occurs through an intrinsic thyroidal mechanism that reduces the thyroidal iodide-transport capacity and thereby allows intrathyroidal iodide to decline to concentrations insufficient to sustain the WolffChaikoff effect.

\section{ACKNOWLEDGMENTS}

The authors are indebted to Miss Ellen Cavanaugh, Mrs. Wendy Lee, and Miss Lillian Eoyang for valuable technical assistance.

\section{REFERENCES}

1. Morton, M. E., I. L. Chaikoff, and S. Rosenfeld. Inhibiting effect of inorganic iodide on the formation in vitro of thyroxine and diiodotyrosine by surviving thyroid tissue. J. biol. Chem. 1944, 154, 381.

2. Wolff, J., and I. L. Chaikoff. Plasma inorganic iodide as a homeostatic regulator of thyroid function. J. biol. Chem. 1948, 174, 555.

3. Wolff, J., I. L. Chaikoff, R. C. Goldberg, and J. R. Meier. The temporary nature of the inhibitory action of excess iodide on organic iodine synthesis in the normal thyroid. Endocrinology 1949, 45, 504.

4. Stanley, M. M. The direct estimation of the rate of thyroid hormone formation in man. The effect of the iodide ion on thyroid iodine utilization. J. clin. Endocr. 1949, 9, 941.

5. Childs, D. S., Jr., F. R. Keating, Jr., J. E. Rall, M. M. D. Williams, and M. H. Power. The effect of varying quantities of inorganic iodide (carrier) on the urinary excretion and thyroidal accumulation of radioiodine in exophthalmic goiter. J. clin. Invest. 1950, 29, 726.

6. Raben, M. S. The paradoxical effects of thiocyanate and of thyrotropin on the organic binding of iodine by the thyroid in the presence of large amounts of iodide. Endocrinology 1949, 45, 296.

7. Galton, V. A., and R. Pitt-Rivers. The effect of excessive iodine on the thyroid of the rat. Endocrinology 1959, 64, 835.

8. Serif, G. S., and S. Kirkwood. The mechanism of the antithyroid action of iodide ion. Endocrinology 1956, 58, 23.
9. Nagataki, S., and S. H. Ingbar. Observations on the separation and measurement of inorganic iodine in rat thyroid glands. Endocrinology 1963, 72, 480.

10. Richards, J. B., and S. H. Ingbar. The effects of propylthiouracil and perchlorate on the biogenesis of thyroid hormone. Endocrinology 1959, 65, 198.

11. Freinkel, N., and S. H. Ingbar. Effect of metabolic inhibitors upon iodide transport in sheep thyroid slices. J. clin. Endocr. 1955, 15, 598.

12. Wood, J. L., and E. F. Williams, Jr. The metabolism of thiocyanate in the rat and its inhibition by propylthiouracil. J. biol. Chem. 1949, 177, 59.

13. Maloof, F., and M. Soodak. The inhibition of the metabolism of thiocyanate in the thyroid of the rat. Endocrinology 1959, 65, 106.

14. Snedecor, G. W. Statistical Methods Applied to Experiments in Agriculture and Biology, 4th ed. Ames, Iowa, Iowa State College Press, 1946.

15. Halmi, N. S. Thyroidal iodide trapping as influenced by serum iodide levels and thyrotrophin. Endocrinology 1954, 54, 97.

16. Schussler, G. C., and S. H. Ingbar. The role of intermediary carbohydrate metabolism in regulating organic iodinations in the thyroid gland. J. clin. Invest. 1961, 40, 1394.

17. Halmi, N. S. Thyroidal iodide transport. Vitam. and Horm. 1961, 19, 133.

18. Sanchez-Martin, J. A., and M. L. Mitchell. Effect of thyrotropin upon the intrathyroidal metabolism of thiocyanate- $S^{35}$. Endocrinology 1960, 67, 325.

19. Alexander, N. M. Iodide peroxidase in rat thyroid and salivary glands and its inhibition by antithyroid compounds. J. biol. Chem. 1959, 234, 1530.

20. Holmes, R. Normal levels of plasma thiocyanate. Nature (Lond.) 1957, 179, 53.

21. Maloof, F., and M. Soodak. The uptake and metabolism of $\mathrm{S}^{35}$ thiourea and thiouracil by the thyroid and other tissues. Endocrinology 1957, 61, 555.

22. Halmi, N. S., B. N. Spirtos, E. M. Bogdanove, and H. J. Lipner. A study of various influences on the iodide concentrating mechanism of the rat thyroid. Endocrinology 1953, 52, 19.

23. Halmi, N. S. Regulation of the rat thyroid in shortterm iodine deficiency. Endocrinology 1954, 54, 216.

24. Halmi, N. S., and B. N. Spirtos. Analysis of the action of propylthiouracil on the pituitary-thyroid axis of rats. Endocrinology 1954, 55, 613.

25. Halmi, N. S., and B. N. Spirtos. Analysis of the modifying effect of dietary iodine levels on the thyroidal response of hypophysectomized rats to thyrotrophin. Endocrinology 1955, 56, 157.

26. VanderLaan, W. P., and R. Caplan. Observations on a relationship between total iodine content and the iodide-concentrating mechanism of the thyroid gland of the rat. Endocrinology 1954, 54, 437.

27. Halmi, N. S., and R. G. Stuelke. Problems of thyroidal self-regulation. Metabolism 1956, 5, 646. 